\title{
ESCOLA CONFESSIONAL FEMININA NA SEGUNDA METADE DO SÉCULO XX: UM ESTUDO ACERCA DO EDUCANDÁRIO NOSSA SENHORA DOS ANJOS/PA
}

\section{FEMALE CONFESSIONAL SCHOOL IN THE SECOND HALF OF THE TWENTIETH CENTURY: A STUDY ABOUT EDUCANDÁRIO NOSSA SENHORA DOS ANJOS / PA}

Gercina Ferreira da SILVA ${ }^{1}$ Universidade do Estado do Pará

Moisés Levy Pinto CRISTO2 Universidade do Estado do Pará

\author{
Darlene da Silva Monteiro dos SANTOS \\ Secretaria de Estado de Educação/PA
}

\begin{abstract}
Resumo: $O$ presente trabalho tem por objetivo analisar alguns aspectos referentes à instalação do Educandário Nossa Senhora dos Anjos, na segunda metade do século $X X$, voltado unicamente à formação de meninas com base em princípios cristãos. As fontes são Louro (1994; 2003), Del Priore (2000), Scott (1995), Foucault (2009), Perrot (1995). Na segunda metade do século XX, as mulheres das camadas burguesas europeias $e$ americanas passaram a ocupar espaços na sociedade, com a permissão de contribuírem com atividades à assistência social, no cuidado de pessoas e na educação de crianças. Este estudo destaca a necessidade de serem levantadas pesquisas na contribuição dos estudos de gênero. $\mathrm{Na}$ década de 50, a elite local de Abaetetuba priorizava a educação feminina. Homens $e$ mulheres recebiam instrução no mesmo ambiente. Essa condição não agradava às famílias católicas. Sendo assim, foi fundado um educandário para instrução de meninas.
\end{abstract}

Palavras-Chave: Educandário. Igreja Católica. Gênero. Educação feminina.

\begin{abstract}
The present work aims to analyze some aspects about the installation of Educandário Nossa Senhora dos Anjos, in the second half of the 20 th century, focused only on the formation of girls based on christian principles. The sources are Louro (1994; 2003), Del Priore (2000), Scott (1995), Foucault (2009), Perrot (1995). In the second half of the 20th century, european and american woman from the bourgeois classes began to occupy spaces in society, with the permission to contribute with activities in social assistance, in the care of people and in the education of children. This study highlights the need to raise research in the contribution of gender studies. In the 1950s, the local elite of Abaetetuba prioritized female education. Men and women received instruction in the same environment. This condition did not please catholic families. Therefore, an school for the instruction of girls is founded.
\end{abstract}

Keywords: Educandário. Catholic Church. Gender. Female education.

\footnotetext{
1 Programa de Pós-Graduação em Educação (PPGED)/Universidade do Estado do Pará (UEPA). E-mail: ferreiragercina@gmail.com.

${ }^{2}$ PPGED/UEPA. E-mail: moiseslevypintocristo@gmail.com.

${ }^{3}$ SEDUC/PA. E-mail: darlene.monte@hotmail.com.
} 


\section{Introdução}

De acordo com Sterns (2017), por volta do quarto milênio antes da Era Cristã, um número de sociedades estava começando a mudar para a fase de organização conhecida por civilização. $\mathrm{O}$ autor coloca a Mesopotâmia e o Egito como civilizações que emergiram depois de três mil e quinhentos anos, e as sociedades agrícolas por volta do quarto milênio, tendo esta desenvolvido novas formas de desigualdades entre homens e mulheres, em um sistema geralmente chamado de patriarcal, com o domínio de maridos e pais. As civilizações seguiram aprofundando o patriarcado, definindo formas distintas que combinavam crenças e instituições mais amplas de cada civilização em particular.

Segundo Meyer (2003), no período da história que data da segunda metade do século XX, as mulheres das camadas burguesas europeias e americanas passaram a ocupar espaços na sociedade, tais como escolas e hospitais, espaços dirigidos e controlados por homens. Às mulheres era dada a permissão de contribuírem na sociedade com atividades inerentes à assistência social, bem como o cuidado de pessoas e a educação de crianças. Para a autora, essas ocupações classificadas como trabalho de mulher, em diferentes sociedades e países, estruturaram os objetos de investigação de muitos dos primeiros estudos desse campo, em que o maior êxito foi o de colocar as mulheres, seus interesses, necessidades e dificuldades em discussão.

Este trabalho tem como objetivo analisar alguns aspectos referentes à instalação do Educandário Nossa Senhora dos Anjos, a partir da segunda metade do século XX, voltado, no início de sua instalação, unicamente à formação das meninas e moças, tendo como discurso dessa formação a preparação de futuras mães e esposas objetivando um melhor desempenho no lar. A educação feminina do século XX era baseada em princípios cristãos, pois se esperava que as mulheres construíssem suas vidas pela imagem da pureza da Virgem Maria, sendo referência para a sociedade e base principal para qualquer projeto educativo. As fontes são analisadas mediante a perspectiva analítica da Nova História Cultural, fundamentada nos estudos de Burke (2008), ao apontar que a realidade é social e culturalmente construída. Dessa forma, a Nova História Cultural nos possibilita construir histórias de pessoas comuns, passando a ter uma compreensão da realidade sobre o fato estudado a partir das representações produzidas pelo sujeito.

Segundo Stearns (2017), a ascensão do feminismo contemporâneo na sociedade, a partir dos anos de 1960, somada às imensas mudanças nos papeis femininos, tanto domésticos quanto profissionais, estimulou uma investigação maciça e abrangente sobre a condição das mulheres no passado e sobre como os padrões antigos têm condicionado as situações atuais. 


\section{A Missão Capuchinha no Pará}

Em 1892, os capuchinhos da Província da Lombardia, na Itália, receberam da Santa Sé, através da Cúria Geral, a incumbência de abrirem uma Missão Indígena na Amazônia, que abrangeu o Norte e o Nordeste do Brasil com objetivos e interesses diversificados, dentre eles a fundação de Missões Indígenas na Alta Amazônia, com o fim de proteger as fronteiras, de acordo com o que pretendia o governo brasileiro e a velha aspiração da Ordem, por tanto tempo barrada pela política do Padroado português, de formar, no Brasil, capuchinhos nativos.

Segundo Zagonel (2001), o período de exploração e fixação da Missão no Brasil começou no ano de 1892, em Pernambuco, com o primeiro grupo de Missionários Lombardos que chegou a Recife, em 24 de abril. Eram eles: Frei Vito de Martinengo, Frei Mansueto de Peveranza, Frei Samuel de Seregno e Frei Emiliano de Goglione, sacerdotes; e os irmãos capuchinhos Frei Paulo de Trescorre e Daniel de Clusone. Em 24 de dezembro do mesmo ano, chegam mais dois missionários: Frei Afonso de CastelLecco e Carlos de São Martinho Olearo, líder dos missionários.

Chegando a Pernambuco, os missionários fizeram alguns meses de estágio para aprenderem o idioma e a respeito da realidade sociorreligiosa e pastoral do Brasil. Frei Carlos era um experiente líder e sob seu comando todos partiram para o Maranhão. De acordo com seus superiores e com o bispo do Maranhão, Dom Alvarenga, os capuchinhos se transferiram para São Luís, próximos das tribos indígenas e a meio caminho para a Amazônia, com o objetivo de restabelecerem a antiga missão indígena, iniciada por Frei José de Loro Piceno, de 1868 a 1882, entre os índios Mearim e do Maranhão. Os missionários partiram para o Pará, e, em 1898, a convite do Governo Estadual, abriram a Colônia Indígena Santo Antônio do Prata; em 1901, estabeleceram residência em Belém, como Capelães do Hospital da Ordem Terceira.

O Governador do Estado do Pará, Paes de Carvalho, percebia a necessidade de, junto com a imigração, dar início a um trabalho de colonização nas áreas habitadas por indígenas, buscando tanto salvaguardar essas áreas quanto proporcionar catequese e instrução para os índios. Dessa forma, começaram as negociações com a ordem religiosa dos missionários capuchinhos Lombardos do Norte do Brasil, vinda da região da Lombardia, em Milão, Itália, para fundar uma missão de civilização e catequese no Pará.

Igarapé-Açu foi escolhido pela ordem capuchinha Lombarda para sediar o Instituto de Educação para índios, filhos de colonos e órfãos, no ano de 1898. A escolha se deu pelo fato de o município ter exuberantes matas e rios de água doce, abrangendo uma área que contemplava as tribos 
dos índios Tembés. No ano de 1897, começaram os contatos da Missão com o Governo do Pará, José Paes de Carvalho, para a fundação de uma "catequese". Esse governador tinha por finalidade civilizar as tribos nômades que habitavam aquela região, tendo recorrido aos religiosos como se fez no passado, como por exemplo, com Anchieta, Melchior de Santa Catarina, José das Chagas, Martin de Nantes e outros (MICHELI, 1986).

O Instituto Santo Antônio do Prata foi criado em 1898, pelo frade capuchinho Carlos de São Martinho, com o financiamento do Governo do Estado, tendo a finalidade de educar meninos índios, sendo chamado de "Instituto da Infância Desvalida Santo Antônio do Prata". No ano de 1905, foi inaugurado o prédio para atender meninas índias, já sob a direção do Frei João Pedro, que viria a ser o fundador da Congregação das Irmãs Missionárias Capuchinhas no Pará. O Instituto de Educação Santo Antônio do Prata transformou-se em uma das mais notáveis instituições educativas do Estado do Pará, no final do século XIX e início do XX. O Instituto ficou prestando serviços locais à comunidade de Igarapé-Açu até 1921, quando foi extinto e transformado em Colônia Agrícola Correcional e depois em Lazarópolis do Prata, para atender pessoas portadoras de hanseníase.

A “Missão Capuchinha do Norte do Brasil” tinha como sede principal o convento do Carmo, localizado no centro comercial de São Luís. Essa missão foi estendida para outros estados como Pará, Ceará, Amazonas e Piauí.

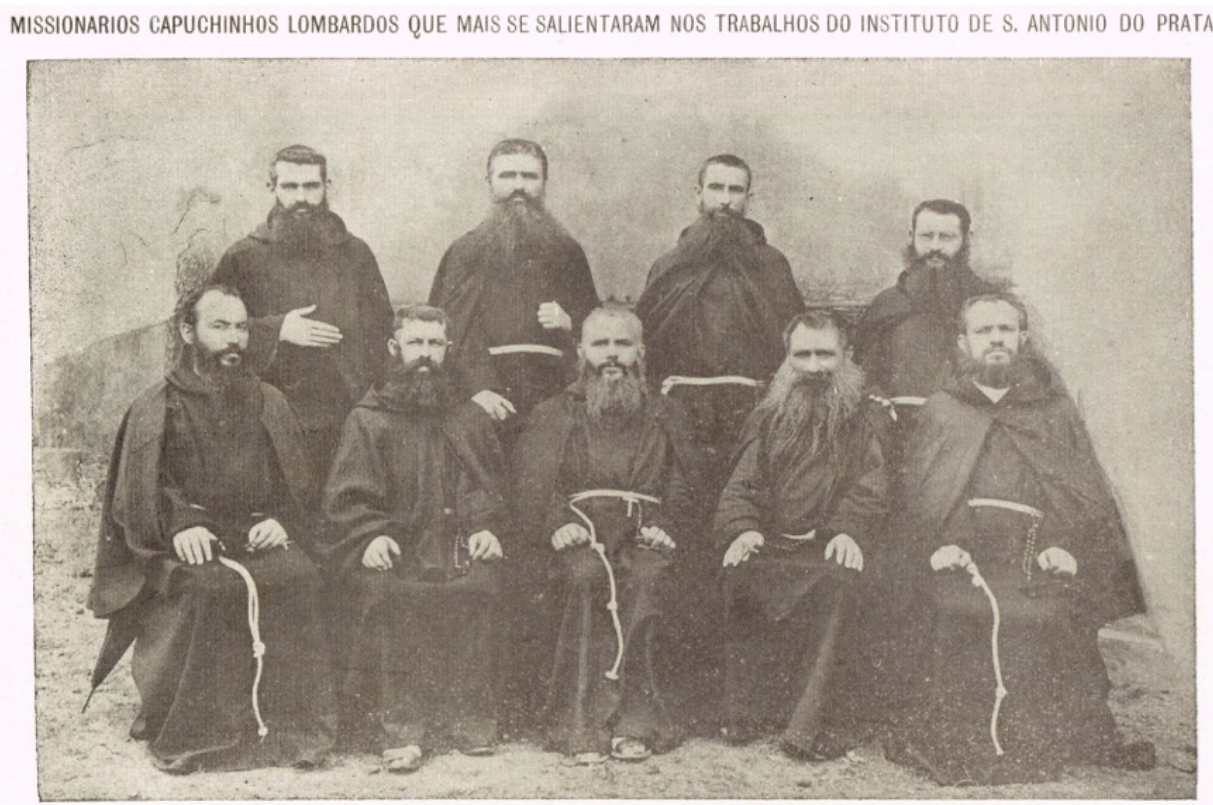

(em pé) Pe. Frei Alfredo de martinengo, Pe. Frei joão Pedro de Sexto são joão, Pe. Frei lourenço De Samarate - (sentados) Pe. Frei MIOU. de Ponteranica, Pe. Frei Estevão de Sexto São Jo ̃ó, Pe. Frei Ca
Pe. Frei Roberto de Castellanza

Fonte: Souza Araújo (1924). 
O trabalho missionário é uma característica da ordem capuchinha no país. O primórdio da missão capuchinha começou durante o II Império (1840-1889). Castilho (2004) relata que, nesse período, as missões capuchinhas tomaram impulso e se espalharam por todo o Brasil, mas somente no fim do Império e início da República é que os missionários da Província de São Carlos da Lombardia chegaram ao Brasil e receberam a tarefa da Santa Sé para abrirem uma Missão Indígena na Amazônia e no Nordeste. Nesse sentido, podemos verificar que o governo brasileiro apoiava o trabalho dos capuchinhos na Amazônia, com a finalidade de catequisar índios, protegendo fronteiras e formando nativos para sua ordem.

\section{A Congregação das Irmãs Missionárias e o Educandário Nossa Senhora dos Anjos}

O Instituto de Educação Santo Antônio do Prata teria como finalidade educar crianças indígenas, tendo como início o instituto masculino. A Ordem religiosa estava com dificuldades para catequisar e "civilizar" os adultos. O fundador da Missão, Frei Carlos, optou por acelerar a construção do instituto de educação para as meninas, pois para ele a educação dessas deveria ser obrigatória e não como uma possibilidade, entendendo-se assim que sem a educação da mulher não pode existir uma "catequese com frutos, visto que a mulher é elemento indispensável da família, base da organização social" (MUNIZ, 1913, p. 32).

Para Frei Carlos, a mulher seria o elo para levar adiante os ensinamentos da civilização e catequese, e o desafio dessa vez seria com as crianças, visto que o mesmo trabalho feito com os adultos não teve boa resultância. Os religiosos defendiam a ideia de que só com o ensinamento da mulher a missão teria bons resultados; um trabalho mais direcionado às meninas com base na educação daria os frutos que os capuchinhos almejavam, tendo-se dado prioridade, portanto, à construção do instituto feminino.

Para os trabalhos educativos no instituto feminino precisava-se de mulheres religiosas, para a Colônia do Prata. Para o governador Augusto Montenegro, seria necessário ter mulheres religiosas brasileiras para cuidar da educação das meninas. A escolha de um grupo de religiosas ficou a cargo do Superior Regular da Missão Frei João Pedro de Sexto São João. Esse fato ocorrido no Pará deu ênfase aos primeiros passos de uma congregação feminina brasileira que mais tarde viria a ser conhecida como a Congregação das Irmãs Missionárias Capuchinhas, fundada na Colônia do Prata, em 18 de dezembro de 1904, por Frei João Pedro de Sexto São João.

Louro (2000) comenta que o Brasil caminhava para o século XX e, nas cidades e povoados, grande parte da população continuava analfabeta. Em sua pesquisa, informa que as escolas para 
meninos eram em maior número do que para meninas. Nesse século, nas escolas fundadas por congregações religiosas, tanto femininas quanto masculinas, homens ensinavam homens e mulheres ensinavam mulheres.

Deveriam ser, eles e elas, pessoas de moral inatacável; suas casas ambientes decentes e saudáveis, uma vez que as famílias lhe confiavam seus filhos e filhas. As tarefas desses mestres e mestras não eram, contudo, exatamente as mesmas. Ler, escrever e contar, saber as quatro operações, mais a doutrina cristã, nisso consistiam os primeiros ensinamentos para ambos os sexos; mas logo algumas distinções apareciam: para os meninos, noções de geometria; para as meninas, bordado e costura (LOURO, 2000, p. 444).

Tendo conseguido as irmãs para administrarem o instituto, Frei João Pedro iniciou os preparativos para a inauguração do instituto feminino no Prata e, em dezembro de 1904, fundou a Congregação das Irmãs Terceiras Regulares da Missão Capuchinha Lombarda no Norte do Brasil.

Imagem 2 - Irmãs cofundadoras na Colônia do Prata

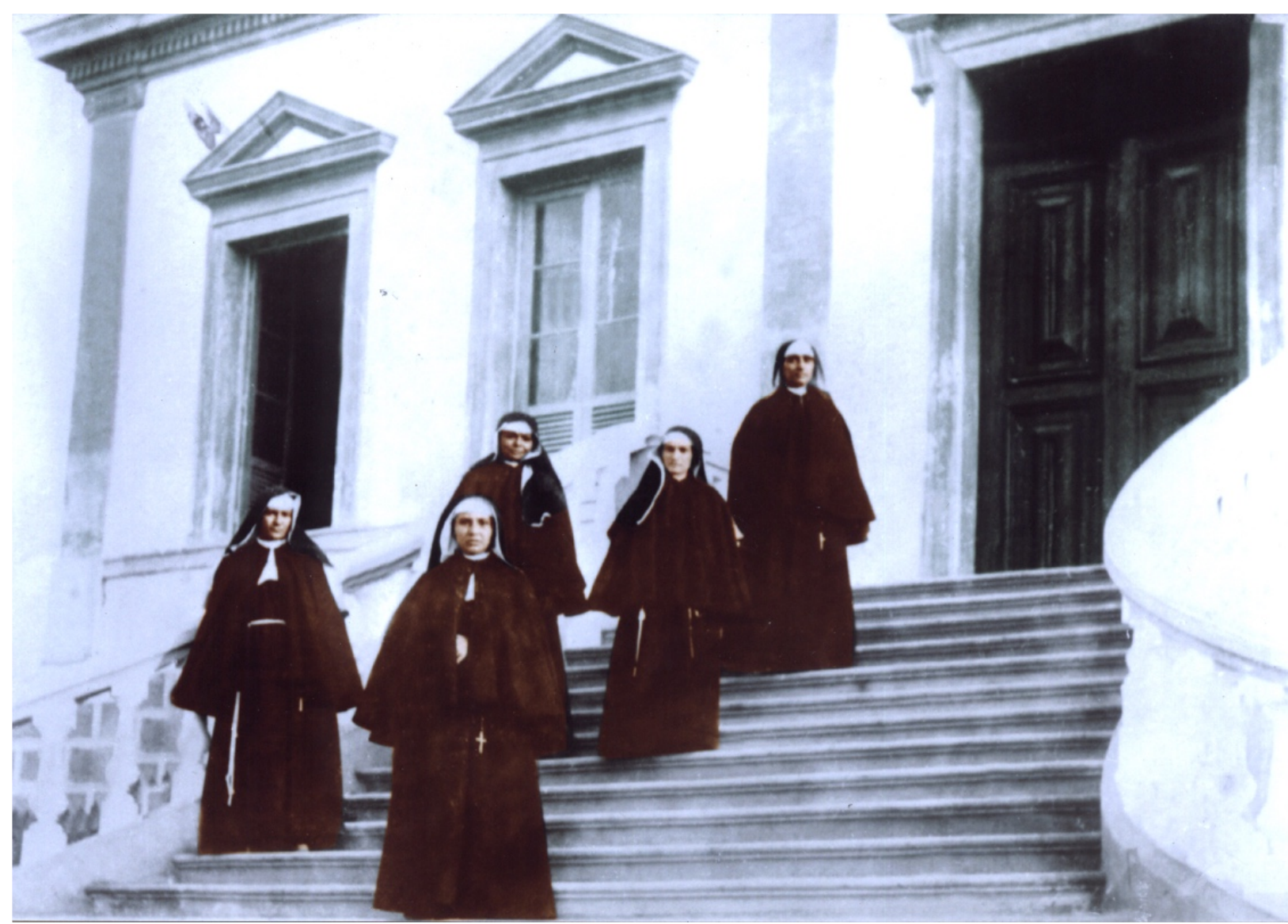

Fonte: www.irmasmissionariascapuchinhas.org. 
De acordo com a primeira Constituição das Irmãs Missionárias Capuchinhas, datada do ano de 1907, o objetivo e função das religiosas consistiriam, em primeiro lugar, na educação e instrução cristã da juventude e, secundariamente, na assistência aos enfermos. Delas seriam cobrados zelo e caridade, na educação e instrução moral, intelectual e religiosa da juventude que lhes fosse entregue, o bem particular de cada aluna, a felicidade da família e o progresso da sociedade (CONSTITUIÇÃO DAS IRMÃS MISSIONÁRIAS CAPUCHINHAS, 1907, p. 14).

Nesses moldes foi fundada a Congregação, e, a partir disso, todos os anos que os capuchinhos estiveram no Prata, as irmãs ficaram responsáveis pela educação das meninas índias e órfãs. No ano de 1921, o Governo do Pará pediu de volta a Colônia do Prata e transformou o lugar em colônia correcional do estado, e depois, em 30 de dezembro de 1922, o vendeu para a União por 300.000\$000 para a ocupação do leprosário Lazarópolis do Prata.

Segundo Castilho (2004), todas as irmãs saíram junto com os frades em 1924, quando o Governo do Pará não podia mais manter as despesas da missão devido à crise da borracha. As irmãs já tinham Casas no Maranhão, sendo uma no município do Grajaú, desde 18 de maio de 1922, o Educandário Sagrada Família; e uma no município de Turiaçu, o Educandário Jesus, Maria e José, iniciado em 1923, quando também foi aberto, no estado do Ceará, município de Fortaleza, o Instituto de Proteção à Infância. A Congregação das Irmãs Missionárias Capuchinhas passou a desenvolver o trabalho de educação e catequese sem a interferência dos frades a partir do dia 29 de agosto de 1924, com a eleição da primeira Superiora Geral, através do I Capítulo Eletivo da Congregação, quando a Congregação passou a ser governada por uma Irmã (Superiora Geral) e não mais pelo Superior dos frades capuchinhos. Tudo foi orientado e organizado pelos frades, visto que as irmãs já tinham 20 anos de caminhada e várias instituições pelo Brasil, passando a ter subsídios financeiros para se manter.

Ainda para Castilho (2004), toda congregação começa diocesana, dependendo tanto espiritualmente do bispo diocesano quanto institucionalmente de onde se encontra a sede geral. Em 1929, a sede geral da Congregação, que era em São Luís, no bairro do Anil, foi transferida para Fortaleza, passando a pertencer à diocese desta cidade. Desde 1926 a Superiora Geral escrevia para Roma, pedindo para a Sagrada Congregação que aprovasse definitivamente a Congregação, mas só foi atendida em 23 de abril de 1951 com o Decreto ad experimentum que durou sete anos. Somente após haver recebido Cartas Testemunhais dos Bispos das Dioceses onde as irmãs trabalhavam é que a Congregação foi aprovada definitivamente, no dia 19 de abril de 1958. A partir desse episódio, a Congregação passou a depender somente da Santa Sé, e os bispos diocesanos nela não interferiram 
mais. A Congregação das Irmãs Missionárias Capuchinhas retornou ao Pará em 1944 para trabalhar na direção da Casa do Pão de Santo Antônio em Belém, localizada na Paróquia dos Capuchinhos.

Segundo Moraes (2000), as Irmãs Missionárias Capuchinhas, chegaram em Abaetetuba no dia 7 de março de 1953, época que os frades administravam a Paróquia de Nossa Senhora da Conceição, atendendo ao convite das autoridades e famílias ilustres do município, que estavam preocupadas com a educação de suas filhas, visto que na cidade existia somente uma escola pública e mista.

Segundo Santos e Júlio (2019), a educação dos séculos XVIII e XIX, proposta para as filhas dos grupos sociais mais favorecidos, era baseada em conteúdos instrutivos, regras e modelos de comportamentos fundamentados principalmente nos princípios morais e religiosos. O Educandário Nossa Senhora dos Anjos, em Abaetetuba, foi pensado para favorecer a educação feminina das filhas de grupos sociais mais favorecidos, afinando-se com as perspectivas da política educacional da época ao querer uma educação diferenciada para as filhas da elite abaetetubense.

De acordo com o livro de Tombamento do ano de 1953, as irmãs missionárias capuchinhas chegaram em Abaetetuba, na região do Baixo Tocantins, com uma comitiva religiosa e pessoas influentes politicamente na sociedade abaetetubense. Na comitiva religiosa estavam: Exmo. Reverendo D. Mário Miranda Villas Boas, arcebispo Metropolitano; Reverendo Frei José Maria, de Manaus; Madre Josefa Maria de Aquiraz, Superiora da Congregação das Irmãs Terceiras Capuchinhas, com mais seis irmãs religiosas; um estudante do Seminário Arquidiocesano, com a missão de fundar o Educandário Nossa Senhora dos Anjos. Dentre as pessoas influentes estava o prefeito de Abaetetuba, Joaquim Mendes Contente.

De acordo com Moraes (2000), a cidade ficou totalmente enfeitada e a população em festa pela presença da comitiva religiosa, aprovada por todos, sendo chamada a atenção de crianças e adultos acompanhando-os em todos os preparativos. Diante da população foi autorizada a doação do prédio antes designado para a construção de um hospital na cidade, obra que não teve sucesso, doado pelo prefeito Joaquim Mendes Contente para as irmãs missionárias capuchinhas em prol da instalação do Educandário.

Para Moraes (2000), o Educandário Nossa Senhora dos Anjos iniciou oferecendo os seguintes cursos: infantil, primário, admissão e profissionalizante doméstico. Na inauguração todos os cursos eram pagos, mas posteriormente houve curso gratuito para crianças pobres, além de uma escola de alfabetização para domésticas e operárias.

No entender de Alves (2014), na segunda metade do século XIX, a sociedade brasileira sofre modificações profundas, pois novos conceitos e valores se fortalecem em função da modernidade que 
vai ganhando espaço em um principal aspecto, que diz respeito à compreensão da educação como forma de civilizar e desenvolver a sociedade brasileira, e esse processo de civilidade em grande parte seria responsabilidade da escola.

O momento que estamos estudando fala muito desse processo, em que um grupo de pessoas se esforçou para trazer ao município uma educação feminina confessional. Essa educação exigida para as mulheres da época, articulada com a Igreja Católica e as elites, vem nos demonstrar sua forte expressão de expansão mediante a catequização por dogmas do catolicismo, considerada um aliado do trabalho educacional às mulheres, tendo bastante êxito na elite abaetetubense, em meados da segunda metade do século XX.

O funcionamento do Educandário Nossa Senhora dos Anjos acontecia em regime de externato e internato. Sobre isso, Moraes (2000) aponta que o internato se destinava a: filhas de famílias que não residiam no município de Abaetetuba, mas que podiam pagar os estudos de suas filhas; órfãs de mãe, que se internavam para serem educadas pelas irmãs; jovens promissoras a uma vida religiosa, que precisariam conviver com as irmãs para que tivessem ensinamentos para avaliação de seu ingresso na congregação.

De acordo com o Livro do Tombo de 1953, a orientação educacional efetivada pelas irmãs se baseava na Lei Orgânica do Ensino Secundário de 1942, que tinha em seu texto recomendações específicas para o tratamento das mulheres, tais como:

1- É recomendável que a educação secundária das mulheres se faça em estabelecimentos de ensino secundário de exclusiva frequência feminina;

2- Nos estabelecimentos de ensino frequentados por homens e mulheres, será a educação ministrada em classes exclusivamente femininas. Este preceito deixará de vigorar por motivo relevante e dado especial autorização pelo Ministério da Educação;

3- Incluir-se-ão na $3^{\mathrm{a}}$ e $4^{\mathrm{a}}$ série do curso ginasial e em todas as séries dos cursos clássicos e científicos a disciplina de Economia Doméstica;

4- A orientação metodológica do Programa terá em mira a natureza da personalidade feminina, assim como a missão da mulher dentro do lar.

Podemos perceber, através da Lei Orgânica do Ensino Secundário, uma preocupação com a educação feminina estabelecida nos moldes cristãos para a devida necessidade de proteger as famílias tradicionais. A sociedade abaetetubense queria estar articulada com as orientações que vigoravam na política nacional, que era "proteger a mulher do trabalho e da esfera política, mantendo-a dentro dos 
limites que lhes eram impostos, cuidando da família e da educação dos filhos” (MORAES, 2000, p.58).

A educação das meninas, mulheres e mães teria que ser à semelhança de Maria; com esse fim as escolas confessionais realizavam orações diárias, romarias, coroação de Maria, tudo que envolvia uma educação "pura" mediante aos preceitos cristãos. Essa educação era exigida com vigor de todas as educandas assistidas no educandário.

Através do símbolo mariano se apelava tanto para a sagrada missão da maternidade quanto para a manutenção da pureza feminina. Esse ideal feminino implicava o recato e o pudor, a busca constante de uma perfeição moral, a aceitação de sacrifícios, a ação educadora dos filhos e filhas. Para Carvalho (2012), não é possível pensar a educação no Brasil sem tomarmos como referência a religião cristã, representada pela igreja católica, influenciando as práticas pedagógicas, nas esferas religiosa e na civil.

Em sua obra Vigiar e Punir, Foucault (2009) mostra que, por meio da disciplina, corpos são docilizados. O autor relata como eram tratados os corpos dos condenados no início do século XVIII. Em sua obra, descreve que, no final do século XVII e início do XX, punições no corpo foram desaparecendo e, depois de alguns anos, o corpo deixou de ser objetivo principal de violência, mas que a violência agora toma uma outra forma, uma forma velada. Essa forma velada ele denomina como "docilização". Com novos objetivos na sociedade industrial, fazia-se necessária a docilização de corpos, pois "um corpo só se torna força útil se é ao mesmo tempo corpo produtivo e corpo submisso" (FOUCAULT, 2009, p. 29).

O processo de escolarização, atravessado por práticas, entrelaçando ações do campo religioso, artístico e literário que põe em evidência o modelo feminino a ser seguido pelas jovens estudantes, tendo como Maria sua maior representação... as famílias eram evolvidas nas atividades religiosas e festivas... Desse modo a educação, a disciplinarização dos corpos e das mentes através de práticas educativas religiosas cotidianas ressaltavam o exemplo de virtudes de Maria a ser adotado pelas alunas (MORAES, 2000, p. 65).

\section{Considerações Finais}

A educação ofertada no Educandário Nossa Senhora dos Anjos era modelo de evangelização e educação, e se expandia na sociedade abaetetubense no decorrer dos anos com uma educação cristã católica de disciplina severa na escola e perpassando para a vida pessoal das educandas, sendo exigidas fora da instituição vida recatada e moral exemplar, como o modo de vestir-se, comportarse, viver em sociedade sem infringir os padrões morais da época. 
Nos estudos da História da Educação, podemos observar que a parceria das instituições religiosas com o estado vem confirmar a manutenção daquelas com benefícios a este, com seus projetos educacionais de corpos e mentes, sem atentar para a política oficial do estado. A instalação e a educação ofertada no Educandário Nossa Senhora dos Anjos, na segunda metade do século XX, confirmam as transformações ocorridas na época, trazendo a educação feminina como uma necessidade e uma educação conservadora instalada na cidade.

Assim, estudar a educação feminina em escolas confessionais, e aqui destacamos o Educandário Nossa Senhora dos Anjos, mostra a necessidade de se levantar pesquisas nessa área, no intuito de contribuir para os estudos de gênero, que nas últimas décadas têm colaborado com a historiografia contemporânea, dando maior visibilidade às questões e reflexões no campo feminino.

\section{Referências}

ALVES, Hercules Alfredo Batista. A educação feminina na região da Campanha-MG: o Collegio Mariano (1867-1907). 2014. Tese (Doutorado em Educação) - Universidade de São Francisco, Itatiba, 2014.

BRASIL. Decreto-Lei $n^{0}$ 4.244, de 9 de abril de 1942. Lei Orgânica do Ensino Secundário. Disponível em: http://www.planalto.gov.br/ccivil 03/decreto-lei/1937-1946/Del4244.htm. Acesso em: 30 nov. 2019.

BURKE, Peter. O que é História Cultural? Rio de Janeiro: Zahar. 2008.

CARVALHO, Maria Goretti Cavalcante de. Projeto educativo das capuchinhas: o franciscanismo na história da educação, em São Luís-MA, desde 1913. São Luís: EDUEMA, 2012.

CASTILHO, Irmã Maria Utília. Irmãs Missionárias Capuchinhas: uma história de amor (feita de luzes e sombras) 1904-2004. Congregação das Irmãs Capuchinhas: Fortaleza, 2004. 
CHAVES, Antônio; GUIRRA, Rafael Cardoso; BURRIONE, Roberta Tavares de Melo; SIMÕES, Flávia Guimarães Amado. Significado de proteção a meninas pobres na Bahia do século XIX. Revista Psicologia em Estudo. Maringá, v. 8, n. especial, p. 85-95, 2003.

EDUCANDÁRIO NOSSA SENHORA DOS ANJOS. Livro de Tombamento do Educandário Nossa Senhora dos Anjos, 1953.

FOUCAULT, Michel. Vigiar e Punir: nascimento da Prisão. Rio de Janeiro: Vozes, 2009.

GOFFMAN, Erving. Manicômios, prisões e conventos. São Paulo: Editora Perspectiva S.A., 1961.

LOURO, Guacira Lopes. Mulheres na sala de aula. In: PRIORE, Mary Del; BASANEZI, Carla (org.). História das Mulheres no Brasil. 3 ed. São Paulo: Contexto, 2000.

MEYER, Dagmar Estermann. Gênero e educação: teoria e política. In: LOURO, Guacira Lopes; NECKEL, Jane Felipe; GOELLNER, Silvana Vilodre (org.). Corpo, gênero e sexualidade: um debate contemporâneo na educação. Petrópolis: Vozes, 2003.

MICHELI, Frei Camilo. O Gigante do Prata. Vice-Província Capuchinha, São Luís-MA, 1986.

MORAES, Joserlina Raimunda Maués de. Escritas de Histórias: formação e prática profissional em uma abordagem autobiográfica. 2000. Dissertação. (Mestrado em Educação). Universidade da Amazônia, Belém, 2000.

MUNIZ, João de Palma. O Instituto Santo Antônio do Prata (Município do Igarapé-Assu). Typ da livraria Escolar: Belém, 1913. 
PARÁ. Constituição das Irmãs Terceiras Regulares da Missão Capuchinha Lombarda do Norte do Brasil. Regra da Ordem Terceira Regular de São Francisco de Assis. Secção Typ. 1907.

SANTOS, Mayra Silva dos; JULIO, Kelly Lislie. A educação feminina nos séculos XVIII e XIX segundo a obra Tesouro de meninas. Anais X Congresso de História da Educação 2019. Disponível em https://xcbhe.com.br/blog/noticias/anais-X-cbhe. Acesso em: 29 nov. 2019.

SOUZA ARAÚJO, Heráclides César. Lazarópolis do Prata: a primeira colônia agrícola de leprosos fundada no Brasil. Belém: Empreza Graphica Amazonia, 1924.

STEARNS, Peter N. História das relações de gênero. Tradução Mirna Pinsky. 2 ed, São Paulo: Contexto, 2017.

ZAGONEL, Carlos Albino. Capuchinhos no Brasil. $1^{\text {a }}$ ed. Conferência dos Capuchinhos no Brasil: Porto Alegre, 2001. 